\title{
GLOBALIZATION AND INTEGRATION
}

\author{
Dr. Prof. Stephen Noerper
}

The autumn winds blow toward me as I journey to a far-off land. D.Natsagdorj

Through the course of our discussions at the School of Foreign Service, we have journeyed to distant lands and understand better the new terrains of this increasingly globalize and integrated world. Dr. Robert Scalapino, distinguished Professor Emeritus at the University of California Berkeley, visiting Ulaanbaatar in September 2000 noted that, "we are witnessing the simultaneous rise of three forces that are innately competitive, "namely internationalism, nationalism, and communalism. The movement of these forces challenges the traditional notions of the nation-state, altering our notions of sovereignty and intervention. There exists the question of the influence of the state in change, the question of decline, the question of alterations in territory, population, and government as the center of authority. We witness ethnicities overlapping borders, as in the case with the Uighur minority in Northwest China, and changing relational identity."

In An Agenda for Peace, former UN Secretary General Boutros BoutrosGhali suggested that 'the time of absolute and exclusive sovereignty...has passed. It is the task of leaders of State today to understand this and to find a balance between the needs of good internal governance and the requirements of an ever more interdependent world". It is our task to expand upon and consider further this phenomenon and place them in the larger context of security and globalization. We need focus the dynamics and challenges of globalization, and in our discussion of political transitions and generational change discuss the dynamics and challenges associated with pluralism and governance.

One aspect of globalization is that of culture, of art, of music. The singer and songwriter Paul Simon authored a commentary on the great American composer, George Gershwin, in the September 6, 1998 New York Times. ("Highbrows and Hits: A Fertile Compound,'2:28). Simon talked about the mix of musical cultures in this manner:

STEPHEN NOERPER is Visiting Professor of International Relations and Fulbright Senior Scholar, School of Foreign Service National University of Mongolia. 
"In truth, cultures and artistic movements influence each other by osmosis, the proximity of different cultures, magnified by the speed of technology, offers an irresistible challenge to artists to rearrange and reinvent languages, musically, visually, and verbally. Cross cultural dialogue is inevitable as generations, philosophies, and artistic movements bang against each other, intermingle, intermarry, and interface."

\section{Economic Integration}

In an international context, interdependence is that mesh-in both security and economic terms. The evidence on the economic front is myriad:

Almost 70 percent of Asia-Pacific economic trade is now with other Asia Pacific countries. This figure compares to intra-regional trade of 64 percent only 10 years ago. It is as high as transatlantic trade, where the countries are a) closer geographically, b) more similar politically, and c) where intra-European trade has been fostered by the European Union trade area.

Cross-border investment flows also have grown dramatically in the AsiaPacific region and have become another major facet of increased Asia-Pacific interdependence. China hosts major investment flows from Hong Kong, Taiwan, and South Korea, while Japanese investments in Southeast Asia have laced those economies more closely to Japan's economy.

Jim Rohwer, author of Asia Rising, noted the tremendous integration of economies through investment and trade linkages. In considering changing trade value patterns, he notes a dramatic increase from only 1985 to 1992 in all directions.

We also see numerous joint ventures between companies of various countries in the Asia-Pacific region-the United States and Japan; South Korea and China; Taiwan and Malaysia; the United States and China, for example-have dramatically increased the interdependent sharing of capital, technology, and expertise within the region. With the current bailout, we will see a surge in joint ventures.

And it is that interdependent sharing, I would suggest, that impacted the course of the Asia financial crisis, both negatively and perhaps in the end, positively. On one hand, the severity was felt throughout the region and we encountered a post-Cold War "domino effect," because of the porous nature of capital investment across Asia. On the other hand, it was that very interdependence that led to solutions, in that suddenly it is in everyone's vested interest to see effective restructuring and resolution of other nation's economic woes. 
Integration begets interdependence. In turn, interdependence speaks to cooperation, common interests, and common needs. It speaks to the notion of greater connectedness.

Interdependence also may be approached in terms of divergence, or symmetry, the notion of symmetric versus asymmetric relationships. How equal are actors or nations?

Imbalance implies asymmetry-for example, a trade imbalance. Disparities in military capabilities, differing sizes of economies, different market sizes imply asymmetry.

These terms speak as well to the two traditional international relations schools of thought, namely realism and liberalism:

Subscribers of realism recognize a referent of the state, of liberalism the population, or citizens. The realist objective is power and survival, the liberal plenty and economic welfare. In terms of world view, subscribers of realism envision anarchy and a globe regulated by balance of power politics, while subscribers of liberalism recognize the importance of international institutions and efforts at cooperation. Realists are concerned with national security, liberal's international security. Now most importantly for this lesson, subscribers of realism argue only relative gains associated with economic exchange and a win-lose situation. Proponents of liberalism see absolute gains, a win-win dimension. In terms of interdependence, subscribers of realism see interdependence as dependence, suggesting a vulnerability that can lead to conflict or war. Proponents of liberalism see an efficiency associated with specialization and prosperity leading to international peace. The cost of war is simply too great relative to economic benefits, suggesting that in the final cost-benefit analysis, cooperation wins out over conflict.

In sum, then how we view interdependence, economic or otherwise, depends on your worldview, how you perceive prospects for conflict or cooperation. The New York Time's Thomas Friedman has posited an alternative model, encouraging us to identify ourselves along the lines of separatists versus integrationists, let-them-eat-cankers versus social-safety-netters.

Beverly Crawford ("Hawks, Doves, but No Owls: International Economic Interdependence and Construction of the New Security Dilemma" in Columbia University's On Security), couched this division by way of economic doves and hawks. Are you an economic dove, subscribing to the belief that interdependence reduces military threats, or a hawk, suggesting increased military vulnerabilities? Do you subscribe to the notion suggested by Robert Keohane and 
Joseph Nye in "Interdependence in World Politics," part of the now classic text Power and Interdependence, that economic interdependence can minimize threats directly by reducing incentives to use force in settling disputes?

Crawford similarly suggests that interdependence reduces threats because it weakens incentives for military conquest; but at the same time, interdependence increases vulnerability and threatens to weaken the state, because potential military resources, particularly high-technology ones, may increasingly be found in global commercial markets. She suggests that increasing globalization of production and exchange presents an economic security dilemma.

Permit me to demonstrate such a dilemma, and here I use an example from Italy, as described in a visual arts review from the September 14, 1997 edition of the Sunday Seattle Times. In a mixed media exhibition titled "Le Tonnare" contemporary artist Donald Feels afforded something of an economic interdependence primer, shedding light on the Mediterranean blue fin tuna industry. In the words of reviewer Robin Updike, the work depicts "how modern air freight and the Japanese sashimi market have changed the ancient Mediterranean fishing industry forever." She explains that 'for his current project Feels traveled to a small island off the west coast of Sicily. For thousands of years the Sicilians fished for blue fin tuna, building elaborate net-and-trap systems to catch the fish, which are some of the strongest and fastest swimmers in the sea. By the late 19th century, enterprising Sicilians were also building canning plants so the fish could be captured and immediately canned. Capturing and canning the fish became the main industries in many of these islands. Now however, the Sicilian blue fin industry is virtually gone. Blue fin meat is among the most highly prized in Tokyo's fresh fish markets, and Japanese industrial trawlers now catch many of the fish before they enter Sicilian waters. Efficient air freight means that the fish can be flown fresh from the trawlers to Japanese markets, where a whole fish goes for $\$ 10,000$ to $\$ 15,000$."

The work "Global Tuna" was reproduced atop the review and featured a montage of a large blue fins, relief's of Sicily and Japan, hands engaged in the buy and sell, a crate and airplane, and portions of sashimi. Noted the artist, "here is a situation involving two ancient cultures, the Sicilians and the Japanese, and neither one is to blame. There is no blame. It's economics. You simply don't can ignore something that's worth $\$ 10,000$ to $\$ 15,000$." He added, "I feel strongly that the world is way more complicated than most of us bother to notice."

But here we have depicted modern transportation and, implied in the buy and sell, the use of modern communication-which speak to something called globalization. 


\section{Defining Globalization}

A variety of definitions abound. Sigmund Bauman, professor emeritus at the University of Leeds and University of Warsaw, notes in his 1998 Columbia University text Globalization: the Human Consequences: "Globalization is on everybody's lips; a fad word fast turning into a shibboleth, a magic incantation."

Clearly, we have seen a progression of terms and ideas in the debate over globalization. One sees globalization described as a phenomenon, a trend, a process, and perhaps most important of late, the international system that replaced the Cold War system, a thesis advanced by Friedman in The Lexus and the Olive Tree (1999).

One of the few criticisms levied about his work is that it is somewhat anecdotal. But anecdotes often are compelling, so let us move to one:

One example drawn from Wednesday's (May 26, 1999) BBC News is that Manchester United-battling Bayern Munich in the European Champions League final-enjoys the unqualified support of many Malaysians. Some 5000 fans belong to the KL branch of the Man United supporters club and have found a haven in the cyber cafe. Says the report, thousands of miles from Old Trafford, all they have to do is type in a search for Manchester United and log into their favorite team's home page. Fan's here say the Internet has become their main source of information, because local newspapers do not carry enough sports news for their taste."

Here we have a cultural melding, suggesting an "increasingly universal culture" and which you may weigh relative to our discussions of identity and trip to the Great Artistic Heritage of Mongolia exhibition.

In an economic sense, globalization means that the factors of production have become increasingly mobile. Capital moves freely across national boundaries. Corporations can easily move their bases of operation to lower cost production areas; technology and information diffuse almost instantly across national boundaries; raw materials are rapidly transported from their source to processing and production sites thousands of miles away (again the case of the bluefish tuna).

\section{Globalization: New or Old?}

Robert Keohane and Joseph Nye noted in an issue of Foreign Affairs ("Power and Interdependence in the Information Age, September/ October 1998, Vol., 77 No.5) that "interdependence among societies in not new. 
What is new is the virtual erasing of costs of communicating over distance as a result of the information revolution."

New York Times Tokyo Bureau Chief Nicholas Kristof in a Sunday edition September 20, 1999 (“As Free-flowing Capital Sinks Nations, Experts Prepare to Rethink System," 1:6) similarly notes that globalization "may not be quite as fresh as it sometimes seems." He opens his piece with the following tale:

"They were the world's richest and shrewdest investors, and they rode a wave of globalization to buy bonds in a promising developing country. When the country defaulted, they were livid. "There should be lunatic asylums for nations as well as individuals, 'one investor wrote in The Morning Post of London, denouncing the defaulting country as 'a nation with whom no contracts can be made.' It all sounds a bit familiar, but the year was 1842 and the developing country was the United States. After defaults by Maryland, Pennsylvania, Mississippi, and Louisiana, the entire United States was blacklisted and scorned on global markets." Kristof also noted that "since at least the 13th century when Florentine merchants lent to the English to pay for King Edward its wars, international capital has roamed the world in search of high returns." What is different is the "scale of capital flows and their abilities to capsize small nations-or even large ones."

The New York Time's Kristof (May 23, 1999, Wk 5, “At This Rate, We'll be Global in Another Hundred years") notes Chinese demand for silver in the 16th through 18th centuries, which bolstered a Spanish empire's finances and slavery as Spanish mining magnates in the Americas traded silver for slave. Down the line, that silver was used in part to purchase Chinese porcelain and silk. A century ago, England and France invested heavily in developing countries. Northwestern University economist Alan Taylor suggests that "to me as an economic historian, it was really the 19th century that represented the birth of the global economy." Yet in the 19th century, trade was mostly in commodities, not manufactured goods, as is now the case. Moreover, today capital movements, investments, are more broadly based (then it was prosperous families; Baron von Rothschild said in 1875 "the world is a city"), flighty, and speculative. Kristof notes that "capital rushes around the world...technology has created an electronic herd (a term of Friedman's) but as yet no electronic cowboys to control the herd."

So again, the key here appears to be mobility, mobility of vast capital resources and mobility based on low cost and ease of information access associated with the information revolution. Keohane and Nye observe that "now 
anyone with a computer can be a desktop publisher, and anyone with a modem can communicate with distant parts of the world at a trivial cost. Earlier transnational flows were heavily controlled by large bureaucracies...such organizations remain important, but the dramatic cheapening of information transmission has opened the field to loosely structured network organizations and even individuals. These NGOs and networks are particularly effective in penetrating states without regard to borders and using domestic constituencies to force political leaders to focus on their preferred agendas."

They go on to note that the "quantity of information available in cyberspace means little by itself; the quality of information and distinctions between types of information are probably more important." As a result of the latter, they suggest a politics of credibility; credibility of information is the "crucial resource and asymmetrical credibility is a key source of power." They note "unlike asymmetrical interdependence in trade, where power goes to those who can afford to hold back or break trade ties, information power flows to those who can edit and credibly validate information."

\section{Globalization: Good or Bad?}

Now the effect of the information and capital flows associated with globalization have been deemed by many as "overwhelmingly good." Overseas Development Council and Goldman Sachs International Chair Peter Sutherland noted in February \{Time Special Report) the "stunning increase in international investment that is building roads, airports, and factories in poorer countries. In the 1990s alone, foreign investors have poured \$1 trillion into developing economies. This trade and investment is raising living standards in some countries faster than many thought possible. Until recently, it took two generations for living standards to double, but in China, living standards now double every ten years."

However, he acknowledges though that while globalization has raised living standards for many, it has made life more difficult for those dislocated by change and "threatens to leave part of the world behind."

Zygmunt Bauman, of Leeds and Warsaw, suggests that "Being local in a globalize world is a sign of social deprivation and degradation." Simply, said the have knots have less. He notes that an "integral part of the globalizing processes is progressive spatial segregation, separation, and exclusion. Neo-tribal and fundamentalist tendencies, which reflect and articulate the experience of people on the receiving end of globalization, are as much legitimate offspring of 
globalization as the widely acclaimed 'hybridization' of top culture. A particular cause for worry is the progressive breakdown in communication between the increasingly global and extraterritorial elites and the ever more 'localized' rest."

Some of you are aware of campaigns to provide computer access to schools and individuals less fortunate. Some NGOs are pushing at the international level for such assistance to developing countries. To move from music and art to astronomy, I was struck by a New Yorker (August 10, 1998) article, titled "Annals of Astronomy: Seeing in the Dark," by Timothy Ferris, who noted that "Earth is by intergalactic standards a local object and indeed belongs to the cluster of galaxies that includes our own galaxy, the Milky Way, and is called by astronomers the Local Group." Ferris described amateur astronomer John Dobson's contention to a group of amateur telescope-makers that "to me it's not so much how big your telescope is, or how accurately your optics are figured, or how beautiful the pictures you can take with it-it's how many people in this vast world less privileged than you have had a chance through your telescope to see and understand this universe." This appears an apt analogy to the need for access among those "globalize" in isolation.

\section{Responses}

Given these challenges and disparities, then, what are the practical responses that you as students of international affairs and future policymakers and /or businesspeople can employ? Friedman describes an emerging global order that "demands an enforcer. That's America's new burden." That contention has stirred a variety of responses.

One example is the US State Department's attempt to adjust to these changing times. US Deputy Secretary of State Talbot's description warrants careful consideration, particularly his focus on new policies and new partners, are they inter-governmental or "multi-multilateral." He suggests a leveraging of scarce resources and improvement of the ability to address transnational threats-a major focus of our next block-"by forming coalitions with non-state actorsmultinational corporations, non-governmental organizations, and international institutions.

(I also like his suggestion that the "very word 'foreign' is becoming obsolete... what happens there matters here and vice versa. That is not only a fact of life and useful shorthand definition of globalization itself, it is also a key selling point for those of us... who are trying to make foreign policy less foreign and more relevant.") 
To quote Pacific Forum CSIS Executive Director Ralph Cossa in a National Bureau of Asian Research (NBR) study, Asia-Pacific multilateralism is "clearly a growth industry today," both at the official, or track I, and non-governmental, or track II, levels.

Foremost among the track I initiatives mentioned in our sub-regional overviews is the ASEAN Regional Forum (ARF), which emerged "to foster the habit of constructive dialogue and consultation on political and security issues of common interest and concern," according to the 1994 Chairman's statement. Of interest to our discussion of the security manifestation of economic interdependence is the ARF's willingness to look beyond its ASEAN membership toward broader Asian concerns. For example, the ASIAN foreign minister's unanimously endorsed early resumption of the inter-Korean talks and have endorsed South Korea's call for a sub-regional forum to address Northeast Asian security concerns.

In speaking of Korea, I note another organization that rides the economic and security nexus, namely the Korean Peninsula Energy Development Organization, KEDO, which former KEDO Executive Director and current US Ambassador to South Korea Stephen Bosworth described as an "important feature on the political landscape in Northeast Asia." Ambassador Bosworth has noted that KEDO might well typify the sort of multilateral cooperation effort we're likely to see in the post-Cold War era: economically-driven but with security underpinnings, especially in terms of building confidence, ad hoc, mission-oriented, temporary, and therefore cost-effective.

In the same vain, I would point out the East-West Center NE Asia Economic Forum support for the formation of a Northeast Asia Development Bank, designed to enhance cooperation and foster development, be it in assisting a divided Korean Peninsula to unify or Mongolia or the Russian Far East to develop further.

In this context, as well, we see a thrust toward preventive diplomacy. The Second ASEAN Regional Forum Chairman's statement more narrowly defines the term as diplomatic efforts which extend beyond confidence building measures, but which stop short of measures to resolve conflict. Such initiatives may include "intermediate" actions aimed at situations where mutual confidence building efforts have deteriorated, but where military conflict has not yet ensued.

In the United Nations, member states attach increased importance to preventive diplomacy as the most cost-effective ways of dispute prevention and 
control. The UN experience in recent years has demonstrated several complementary forms of preventive activity: preventive deployment, preventive disarmament, preventive humanitarian action, and preventive peace-building, the latter of which may involve action aimed at good governance, human rights, and economic and social development. According to the UN Department of Political Affairs, it is for this reason that the Secretary-General in 1996 re-labeled "preventive diplomacy" "preventive action."

Another aspect of preventive diplomacy that grows out of our thinking about interdependence and globalization concerns the range of appropriate action specific to regional, international, or non-governmental organizations. In her chapter "Regional and Sub-regional Organizations in International Conflict Management," in Chester Crocker et al.'s Managing Global Chaos: Source of and Response to International Conflict, Ruth Wedgwood observes that "in the last five years, there has been a salient pattern of double-teaming among international organizations; major powers with security interests and the UN Security Council have worked effectively with ad hoc regional groupings, formal regional organizations, and specific sub-regional groups to adapt their charters for new uses." Scott Snyder of the Asia Foundation Korea has suggested that "given the effectiveness of coordinated responses among international and regional organizations, the opportunity to effectively harmonize regional and international efforts at preventive diplomacy should not be missed." This doubleteaming, $>$ coordination, harmonization are part of what Talbot termed effective "multi-multilateralism."

Lastly, I would like to focus briefly on the US defense establishment's attempt to address globalization and security through, the notion of "preventive defense." In a 1996 Foreign Affairs article, then-US Secretary of Defense William Perry suggested that "today the United States has a unique historical opportunity to foster peace through preventive defense." He goes on to cite two similar opportunities earlier this century, namely one missed in the form of an isolationist America's rejection of the League of Nations and one seized upon in a post-World War II " path of engagement" that entailed the Marshall Plan, what he labels the "epitome of preventive defense." In noting that preventive defense serves "to build openness and trust between nations." Secretary Perry cited the Marshall Center. In Germany and Asia-Pacific Center in Hawaii as prime examples. In I a May 1996 Foreign Policy Backgrounder on his remarks to the 29th International General Meeting of the Pacific Basin Economic Council (PBEC), then-Secretary Perry outlined as a "pillar" of preventive defense the "promotion 
of multilateral security initiatives designed to reduce tension and build regional confidence."

Let me conclude, as we began, with a quote from the world of music that speaks to us by way of security and strategy:

In a feature on resurgent interest in Brazilian Tropically, a style popularized in the late 1960s and 1970s by musician Tom Ze and others, New York Times Magazine editorial director Gerald Marzorati ("Tropicalia, Agora," April 25, 1999, pp.50-1) suggests - as we might of globalization and integration - that:

"It represents something more, a recognition that 'center' and "periphery' are becoming more proximate and less clearly delineated, that borders are growing more porous back and forth... going omni directionally global... it may well be that global-scale mixing-sampling-layering is the only...strategy that suits a quickened world of clicks and info-fragments, jumbo jet migrations, and hyphenated identities."

Dr. Prof. Stephen Noerper is Visiting Professor of International Relations and Fulbright Senior Scholar, Mongolia. He is an occasional lecturer at Mongolia's Academy of Sciences and a Senior Associate of the Nautilus Institute.Professor Noerper may be contacted at noerpers@hotmail.com 